\title{
Power Quality Enhancement in Grid Connected Hybrid PV/WT System using Tree Seed Algorithm with RNN \\ ${ }^{* 1}$ K.Sudarsan, ${ }^{2}$ G.Sreenivasan \\ ${ }^{1}$ Department of Electrical and Electronics Engineering, JNTUA University, Anantapuramu \\ ${ }^{2}$ Department of Electrical and Electronics Engineering, Srinivasa Ramanujan Institute of Technology, Anantapuramu \\ Email: suda.abhi@gmail.com,gsn.anusree@gmail.com
}

\author{
Received: 06th December 2019, Accepted: 20th January 2020, Published: 30th April 2020
}

\begin{abstract}
Renewable energy becomes a key contributor to our modern society, but their integration to power grid poses significant technical challenges. The major power quality concerns are voltage sag, swell, fluctuations, distortion, and interruption which are caused by noncontrollable variability of renewable energy resources. In this paper, the D-STATCOM device is utilized for compensating power from PV and wind ranch. To control the power flow efficient control techniques are exercised. Recurrent Neural Network (RNN) with Tree Seed Algorithm (TSA) is employed as a control scheme. Distribution Static Synchronous Compensator (DSTATCOM) can be adopted for reactive power compensation and for reducing the problems caused by the system. The proposed system will be anlyzed in MATLAB/Simulink platform. In order to evaluate the effectiveness of the suggested method, this is compared with the existing methods, such as PSO-RNN and CSORNN techniques.
\end{abstract}

\section{Keywords}

PV-D-STATCOM, TSA (Tree Seed Algorithm), PSO (Particle Swarm Optimization), CSO (Chicken Swarm Optimization), RNN (Recurrent Neural Network)

\section{Introduction}

Renewable energy such as wind turbines and solar photovoltaic (PV) systems use natural resources and provide desirable green energy. On the one hand, the intermittent nature of renewable energy will intensify the volatility of power flow [1]. However, unlike conventional energy generation, renewable energy is intermittent in nature[2]. PV inverter is established as the interface among the PV array and the grid to change dc to ac [3].For controlling the voltage and the power flow, reactive power compensation is required [4]. Currently, multi-day Flexible AC Transmission System (FACTS) devices are large progressively conceived for elaborating the Available Transfer Capacity (ATC) of existing lines. PV sun ranch creates original power amid day term and amid night term they are completely sitting still [5].

The initial component of PV solar plant is a voltage origin inverter or converter which is additionally a centerpiece of FACTS device STATCOM [6].A unique concept of applying PV solar ranch as STATCOM among night term for rendering various grid support functions as well as for rendering the same benefits among day term with inverter capacity remaining original power generation by voltage origin converter based FACTS device [7].The use of a PV solar system goes about as a STATCOM applying the appraised inverter limit during night term and the inverter limit staying after real power generation during the day term. The paper is organized as follows. Design of the PV-STATCOM system and suggested control structure is afforded in section 3 and 4 . To establish the effectiveness of the suggested approach, the simulation results are introduced in Section 5. Finally, the conclusion is afforded in Section 6.

\section{Recent Research Works: An Overview}

In this literature review already existed techniques for voltage control issues of PV solar ranch were listed below, A new smart PV inverter generates as STATCOM, mentioned PV-STATCOM, for voltage control has been implemented by Rajiv et al. [8]. It generates as a STATCOM with complete inverter capacity in nightterms as well as among any term of the day to render critical grid support. The Low Voltage Ride Through (LVRT) performance of the PV-STATCOM was established through both simulations and laboratory by applying dSPACE control. An SSR concept in a capacitive arrangement compensated DFIG-based wind ranch has been invented by Mohammadpour et al. [9]. An applying both modular examination and time-domain simulation, it was established that the DFIG wind ranch was conceivably uncertain since of the SSR mode. Keeping in mind the end aim to damp the SSR, the Rotor-Side Converter (RSC) and Grid-Side Converter (GSC) controllers of the DFIG were applied. The aim was to outline a straightforward compare SSR damping controller (SSRDC) by legitimately gathering an important input control signal (ICS) to the SSRDC.

On the distribution system, the objective is to ensure the development of high levels of PV without effect on clients. For damping, most of the methods applying FACTS applications and SSR have a few disadvantages. 
Grid association issues, for example, prediction and control, voltage rise and harmonics. Moreover, Static Synchronous Series Compensator (SSSC) has been the execution of power oscillation damping, stability development, and frequency stabilization. The suggested technique is the design of PV-STATCOM for maximal utilization of the day and night term. In the below section, the design technique and control structures are elaborated.

\section{Proposed D-Statcom based Control}

In this system, PV-D-STATCOM is utilized for compensating its DC-side voltage. Here PV and wind energy sources are utilized for generating electricity. PV is considered as a first source for power generation in this work if it is absent means wind energy is considered. At dayterm PV and wind systems produce power. The energy generated from wind and PV is given to the D-STATCOM, which acts as an inverter in this work. It is used to regulate voltage. For control voltage sag, swell, fluctuation, interruption and distortion, these DSTATCOM devices are applied. The structure of this technology is illustrated in Fig. 1. The capacitors are applied for soft switching and also minimize the voltage spike.

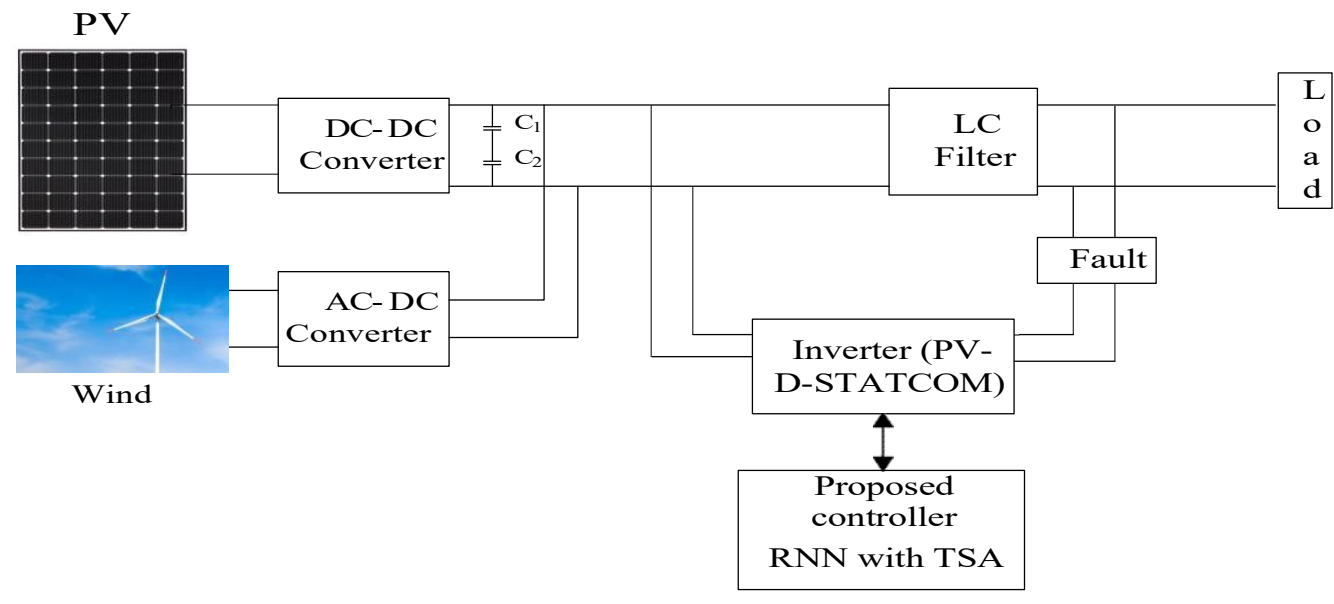

Fig. 1: Proposed D-STATCOM Based Control Structure

For control of PV-D-STATCOM , a controller is proposed, based on RNN with TSA. The output from the DSTATCOM is given to the control structure and control operation takes place until the required compensation is achieved. The PV inverter operates as D-STATCOM during 24 hours to control the voltage and reactive power compensation. For controlling fault, some fault signals are afforded to the D-STATCOM device. The day term, $\mathrm{PV}$ and wind energy generation are replacing the load demand and the inverter act as a conventional inverter. The night term, PV is absent condition and wind energy generation does not replace the load demand, which is inverter act as D-STATCOM for compensation and control the voltage by the utilization of the suggested controller.

\section{Objective Function}

In this work, the main objective is controlling PQ issues and reducing faults such as voltage sag, swell, fluctuation, distortion, and interruption. For reducing these issues ANN with TSA is exercised and faults are reduced efficiently. The power quality issues of the system mainly depend on the real and reactive power, voltage, harmonics and etc. So, the PQ of the system is maintained by control the above-mentioned parameters. Therefore, the problem can be formulated as the objective function with the specified constraints.

Min $\delta_{O F}(x, u)$

Subject to $P(x, u)=0$

$S(x, u) \leq 0$

$\delta_{O F}$ is the objective function, is the equality constraints and is the inequality constraints that depend on the control variables $x$ and $u$.Here, the adaptive algorithm is developed for improving the performance of DSTATCOM.

Development of Adaptive Tree Seed Algorithm with aid of RNN Technique

In this section, the suggested method is used for enhancing the D-STATCOM performance and minimizing the harmonics of the system. For achieving the objective function, the reference current, reference voltage, regulation of dc voltage and tuning of the PID controller is performed and specified their parameters. Here, the error voltage and load side error current are taken as input parameters for the suggested algorithm. The PQ issues, real and reactive power injection can be determined from the inputs. The procedure of the suggested algorithm is explained as follows:

Adaptive TSA algorithm

TSA has a specific relationship between trees and seeds, which provide possible solutions for optimization 
problems. In this section TSA Algorithm used for enhancing the operation of D- STATCOM and minimize the PQ issues of the system. Here the error voltage and change of error voltage, consider as agents, are taken as inputs to TSA Algorithm. The step-by-step procedure is explained as follows:

Step 1: Initialize the inputs randomly. Here, the inputs, gain parameters are considered as the trees.

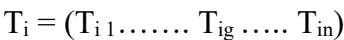

Where, $\mathrm{n}$ is the search tree position, $T_{\mathrm{ig}}$ is the $i^{\text {th }}$ position of the tree in the $g^{\text {th }}$ dimension

Step 2: The minimum range (values) of PQ issues gives the fitness function of tree position and seed position. The fitness function of the agent is calculated as follows:

$\mathrm{F}_{\mathrm{i}}=\min (\mathrm{PQ})_{\mathrm{i}}$

Where $P Q_{i}$ is the power quality issue. After that, new seeds production is calculated.

Step 3: Find the minimum error voltage using equation (3), which gives the best solution from the population.

$\mathrm{T}_{\text {bestj }}=\min \left\{\mathrm{f}\left(\mathrm{T}_{\mathrm{i}}\right)\right\} \quad \mathrm{i}=1,2,3 \ldots \ldots \mathrm{N}$

Here, $\mathrm{N}$ is the number of trees in the population

Step4: The random search solution for reduced the error voltage in the D-STATCOM. Select the best seed and compare it with the tree. The update this dimension using equation (4) and (5) respectively.

$\zeta_{\mathrm{ij}}=\mathrm{T}_{\mathrm{ij}}+\vartheta_{\mathrm{ij}} \cdot \mathrm{u}\left(\mathrm{T}_{\text {bestj }}-\mathrm{T}_{\mathrm{rj}}\right)$

$\zeta_{\mathrm{ij}}=\mathrm{T}_{\mathrm{ij}}+\vartheta_{\mathrm{ij}} \cdot \mathrm{u}\left(\mathrm{T}_{\text {bestj }}-\mathrm{T}_{\mathrm{rj}}\right)$

Where, $\zeta_{\mathrm{ij}}$ is the $j^{\text {th }}$ dimension of the $i^{\text {th }}$ seed of the tree, $\mathrm{T}_{\mathrm{ij}}$ is the $j^{\text {th }}$ dimension of the $\mathrm{i}^{\text {th }}$ tree, $\mathrm{T}_{\text {bestj }}$ represents the $j^{\text {th }}$ dimension of the best tree position obtained, $\mathrm{T}_{\mathrm{rj}}$ is the $j^{\text {th }}$ dimension of the $\mathrm{r}^{\text {th }}$ tree which is randomly selected from the population and $\vartheta$ is the scaling factor which is randomly generated in the $[-1,1]$ interval

Step 5: Optimize the parameters using RNN technique. ( explained in section 4.2)

Step 6: Select the best solution, which is better than the previous, and substitutes it for the previous best solution.

Step 7: Calculate the fitness function and if there is a better solution, find the best search solution. Let $\mathrm{t}=1$ reaches Maxgen, the algorithm is finished. Here, the minimum PQ issues, voltage, and gain parameters are calculated. Then the analysis part is discussed in the following section.

\section{Recurrent Neural Network for Learning Parameter Prediction}

The RNN is the manufactured preparing and testing calculation, which takes a shot at the premise of a machine learning approach that models a human mind and comprises of various simulated neurons. The learning undertaking is given as illustrations, which are known as preparing cases. Typically RNN has three layers like information layer, concealed layer, and the output layer.

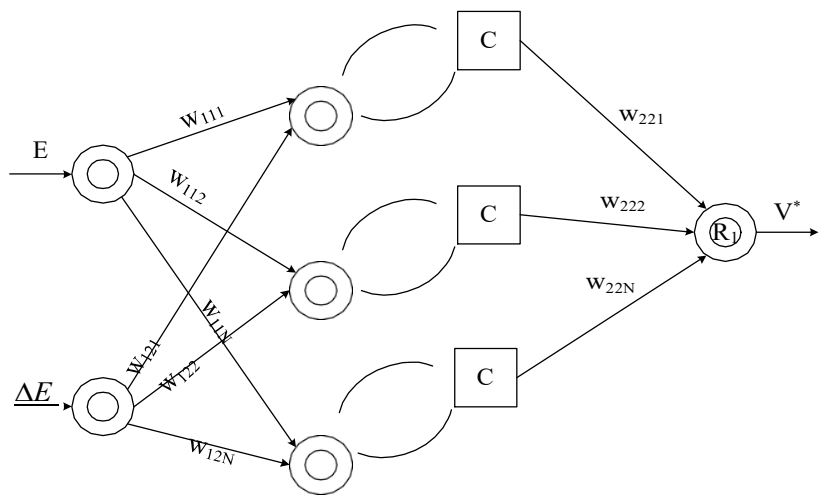

Fig. 2: Framework of Recurrent Layer Neural Network

Here, the info layer comprises of mistake sign $\left(V_{E}\right)$ and change of blunder sign $\left(\Delta V_{E}\right)$. The output target layer is the control law (V"), which is created for directing the heap reference voltages. The RNN yield is given to the inverter voltage controller. Additionally the RNN has connection layer, which holds exercises of the repetitive layer from the last time step. This preparation procedure uses the regulated learning process. The RNN structure is shown in Fig. 2. The preparation procedure is explained below. 


\section{(i) Supervised Learning and Training Process}

The RNN is prepared by utilizing back engendering through time delay calculation with Bayesian control. The RNN procedure depends on the forward and reverse path. This area portrays the preparation procedure of the RNN [10]. Here, the administering learning law of the angle plunge is utilized to prepare the RNN at the end of the reinstatement procedure.

$\mathrm{E}_{\mathrm{C}}=\theta_{\mathrm{d}}-\theta_{\text {nor }}$

Where $\theta_{\text {nor }}$ is the real exchanging edge, $\theta_{\mathrm{d}}$ is supplied by the Newton Raphson Algorithm and $\mathrm{E}_{\mathrm{C}}$ is the blunder capacity. The blunder computation and weight redesigning are clarified in the accompanying.

Layer 1: This layer is employed to update the weight of the $\mathrm{W}^{2} \mathrm{bc}$ At this juncture, the updated weight is offered by the subsequent equation (10),

$\mathrm{W}^{2}{ }_{\mathrm{bc}}(\mathrm{n}+1)=\mathrm{W}^{2} \mathrm{bc}(\mathrm{n})+\eta_{\mathrm{bc}} \Delta \mathrm{W}^{2} \mathrm{bc}(\mathrm{n})$

Where instant weight function is computed as equation (11) and the error term is devised as equation (12),

$\Delta \mathrm{W}^{2} \mathrm{bc}=\partial \mathrm{E} / \partial \mathrm{R}_{\mathrm{c}}{ }^{3}=\delta_{\mathrm{c}} \mathrm{R}_{\mathrm{b}}$

$\delta_{\mathrm{c}}=\partial \mathrm{E} / \partial \mathrm{R}_{\mathrm{c}}{ }^{3}=\left(\partial \mathrm{E} / \partial \mathrm{e}_{\mathrm{s}}\right)\left(\partial \mathrm{e}_{\mathrm{s}} / \partial \mathrm{R}_{\mathrm{c}}{ }^{3}\right)$

Where $\delta_{\mathrm{c}}$ is proliferate the error term, $\eta_{\mathrm{bc}}$ is the learning rate for changing the parameter $\mathrm{W}^{2} \mathrm{bc}$.

Layer 2: This layer performs multiplication function, the updated rule for $\mathrm{W}^{2}{ }_{\mathrm{b}}$ and $\mathrm{W}^{2}$ ab is depicted by the subsequent equation (13) and (14),

$\mathrm{W}^{2}{ }_{\mathrm{b}}(\mathrm{n}+1)=\mathrm{W}^{2} \mathrm{~b}(\mathrm{n})+\eta_{\mathrm{b}} \Delta \mathrm{W}_{\mathrm{b}}^{2}(\mathrm{n})$

$\mathrm{W}^{2}{ }_{\mathrm{ab}}(\mathrm{n}+1)=\mathrm{W}^{2}{ }_{\mathrm{ab}}(\mathrm{n})+\eta_{\mathrm{ab}} \Delta \mathrm{W}^{2}{ }_{\mathrm{ab}}(\mathrm{n})$

Where, the instant weight is approximate an equation (15) and (16),

$\Delta \mathrm{W}_{\mathrm{b}}^{2}=-\partial \mathrm{E} / \partial \mathrm{W}_{\mathrm{b}}^{2}=\delta_{\mathrm{c}} \mathrm{W}_{\mathrm{bc}}^{2} \mathrm{P}_{\mathrm{b}}^{2}$

$\Delta \mathrm{W}_{\mathrm{ab}}^{2}=-\partial \mathrm{E} / \partial \mathrm{W}_{\mathrm{ab}}^{2}=\delta_{\mathrm{c}} \partial \mathrm{W}^{2}{ }_{\mathrm{bc}} \mathrm{Q}_{\mathrm{ab}}{ }^{2}$

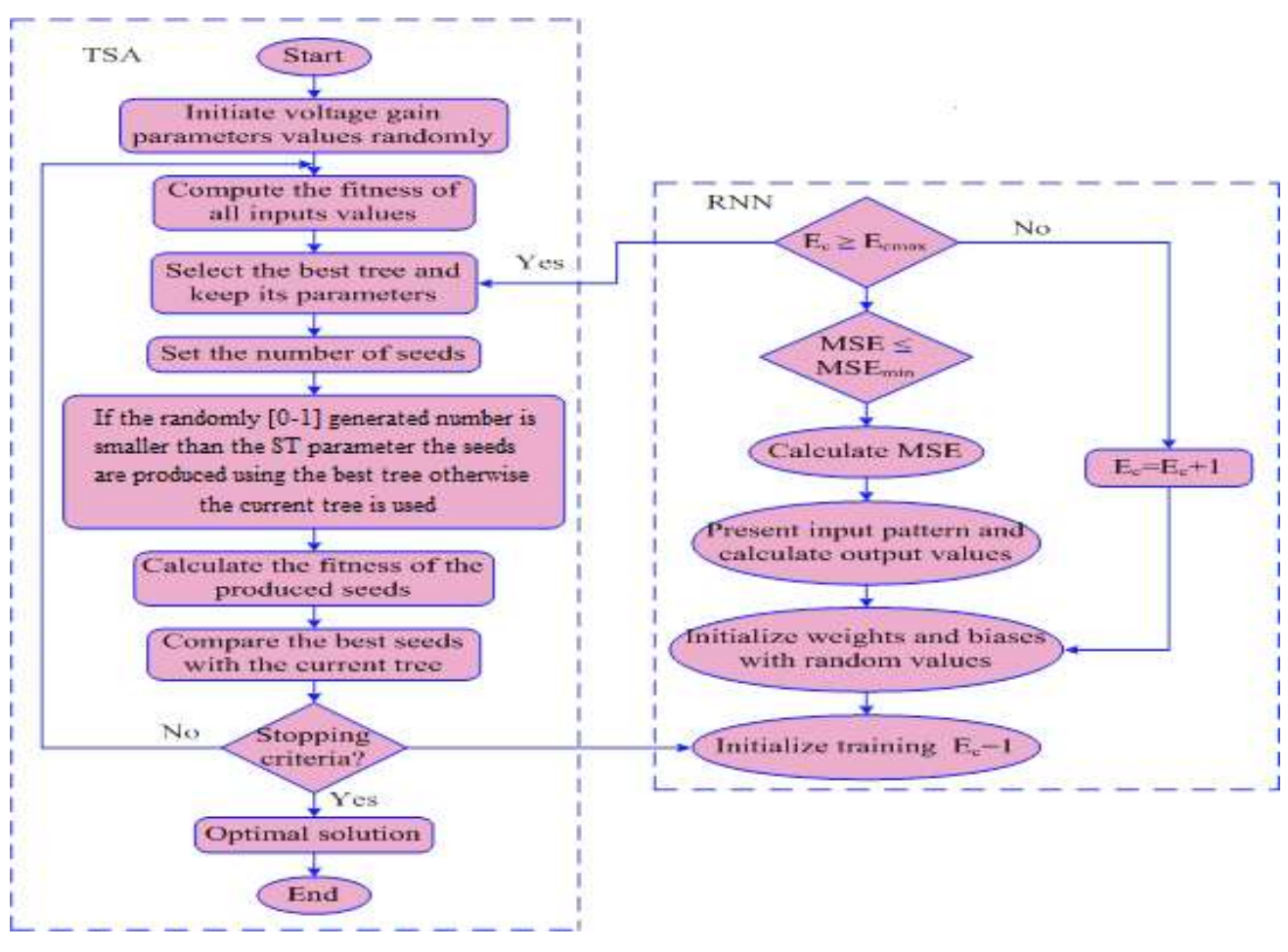

Fig. 3: Structure of the Proposed Adaptive Technique 
Where $\eta_{b}$ and $\eta_{a b}$ are the individual learning rates for changing the parameters $\mathrm{W}^{2}{ }_{\mathrm{b}}$ and $\mathrm{W}^{2}{ }_{\mathrm{ab}}, \mathrm{W}^{2}{ }_{\mathrm{b}}, \mathrm{W}^{2}{ }_{\mathrm{ab}}$ and $\mathrm{W}^{2}{ }_{\mathrm{bc}}$ are the tuning parameters. Here a learning calculation is inferred that drives $\mathrm{E}$ to zero. Once the procedure is done, the RNN is prepared to give the voltage error value minimization. At last the RNN yield is given to the PWM. The proposed method structure is portrayed inFig.3. The detailed analysis of the execution is described in section 5 .

\section{Results and Discussion}

In this paper, the analysis of PV-D-STATCOM based controller is utilized to control the voltage sag, swell, fluctuation, distortion and interruption. The operating performance of the controller is anlyzed with the MATLAB/Simulink platform. The effectiveness of the control method is analyzed and compared with the traditional approaches such as CSO-RNN and PSO-RNN. Mainly, the power management in the PV-DSTATCOM operation with the compensation of the load at dayterm and nightterm are achieved through the utilization of the TSA algorithm. Fig. 4 illustrates the MATLAB/Simulink implementation model of the suggested controller in PV-D-STATCOM. Table 1 shows the implementation parameters of the suggested model.

Table 1: Parameters of the Suggested Method

\begin{tabular}{|c|c|}
\hline Parameter & Value \\
\hline LC filter Inductance & $250 \mathrm{e}-6(\mathrm{H})$ \\
\hline LC filter Capacitance & $1000 \mathrm{e}-6(\mathrm{~F})$ \\
\hline Frequency & $60(\mathrm{~Hz})$ \\
\hline Base voltage & $120 \mathrm{e} 3(\mathrm{~V})$ \\
\hline Nominal Power & $100 \mathrm{e} 3(\mathrm{~W})$ \\
\hline Magnetization Resistance & $500(\mathrm{Ohm})$ \\
\hline Magnetization Inductance & $500(\mathrm{H})$ \\
\hline
\end{tabular}

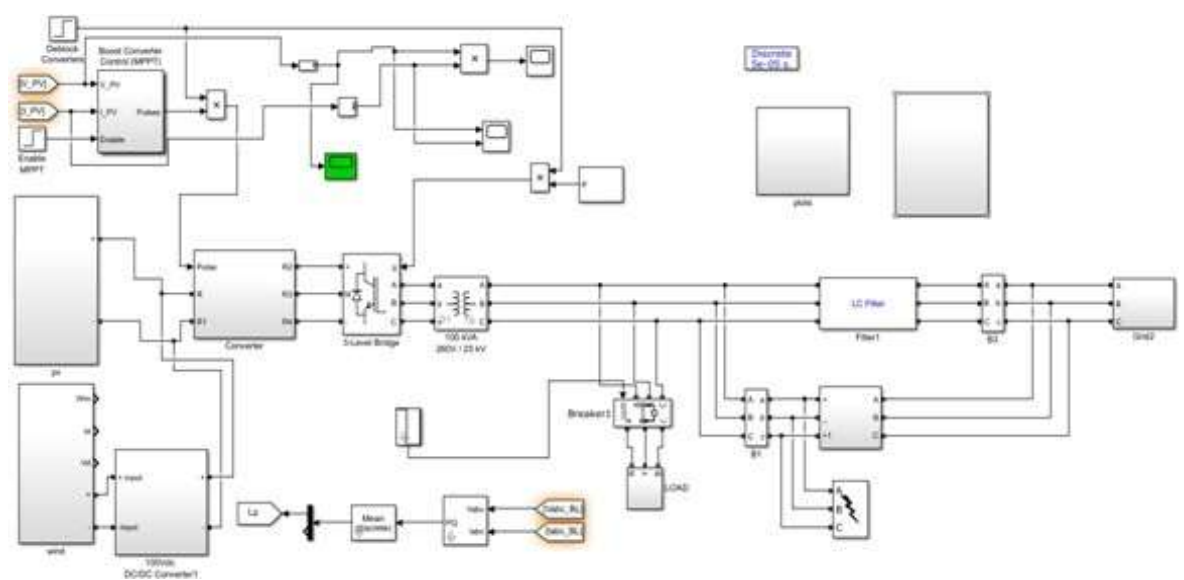

Fig. 4: Simulink Model of Proposed Control Technique

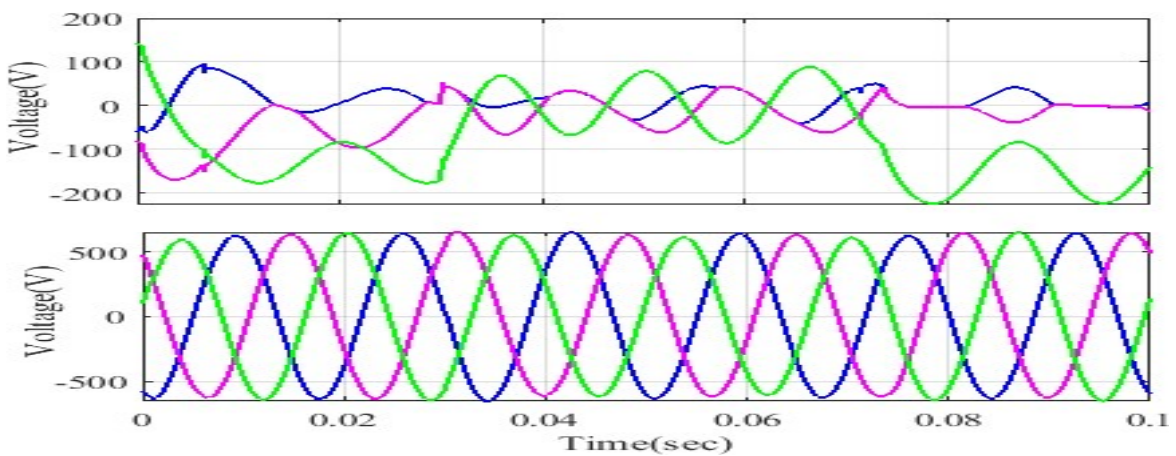

(a) 


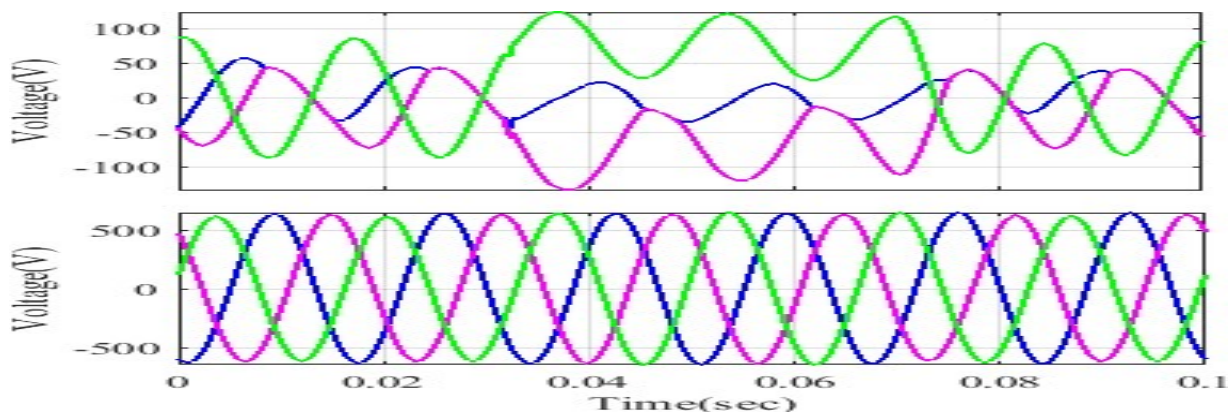

(b)
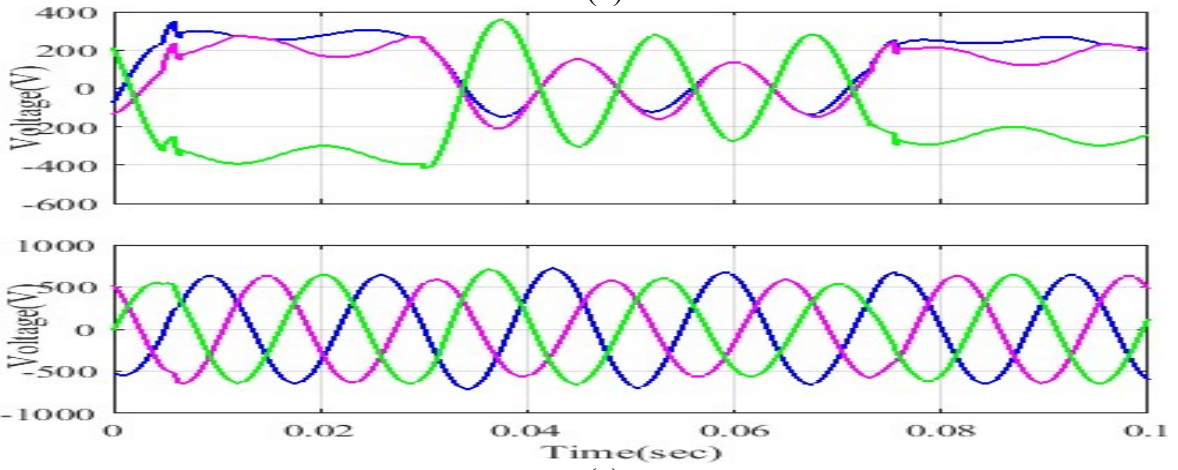

(c)
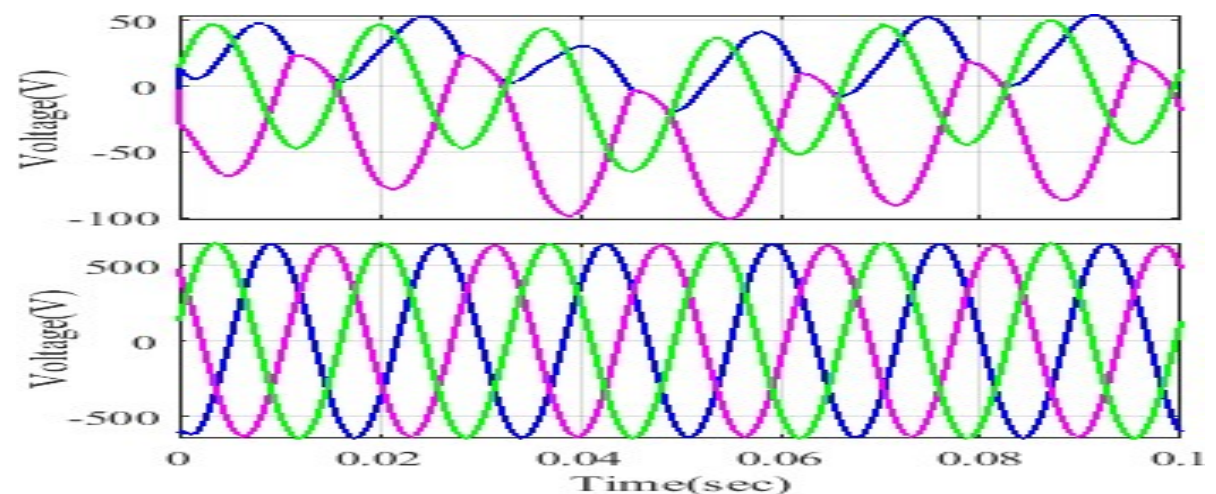

(d)
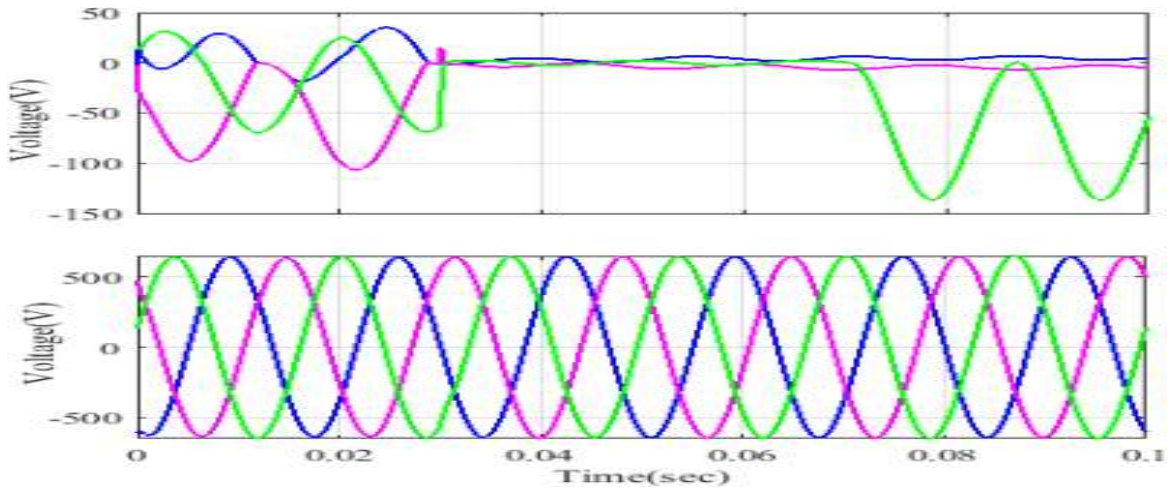

(e)

Fig. 5 Analysis of (a) Voltage Sag (b) Swell (c) Fluctuation (d) Distortion and (e) Interruption 


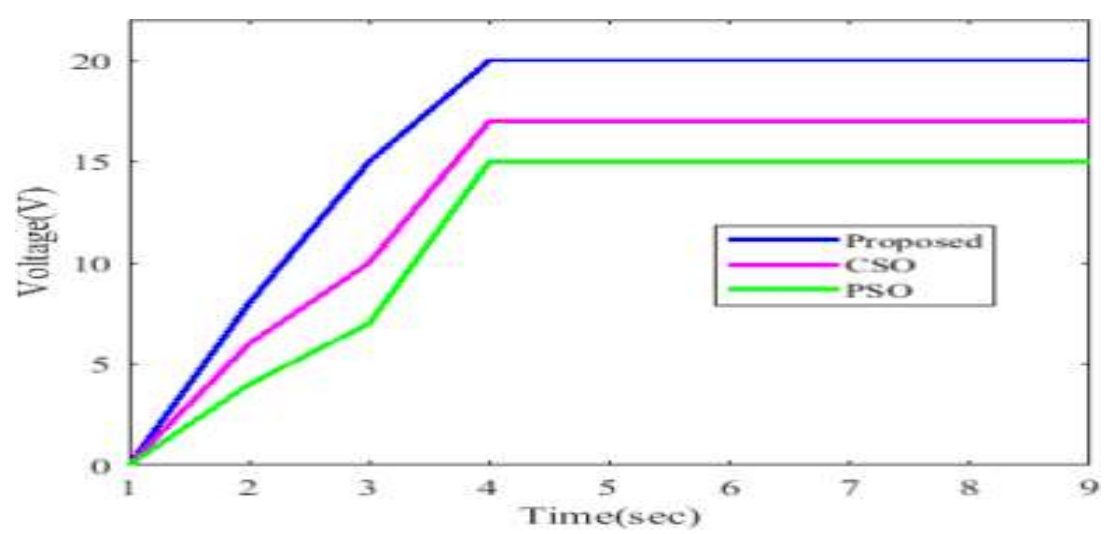

Fig. 6: Analysis of DC Link Voltage

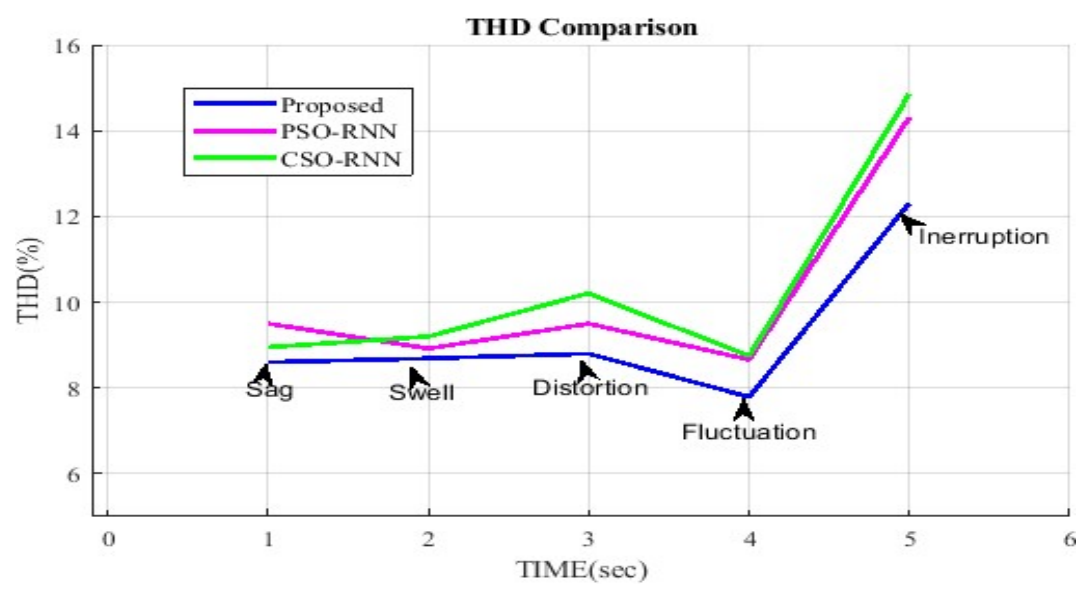

Fig. 7: Comparison Analysis of THD

Table 2: Values of THD for Various Problems

\begin{tabular}{|c|c|c|c|c|}
\hline PQ issues & Parameter & $\begin{array}{c}\text { PSO-RNN } \\
(\%)\end{array}$ & $\begin{array}{c}\text { CSO-RNN } \\
(\%)\end{array}$ & $\begin{array}{c}\text { Proposed } \\
(\%)\end{array}$ \\
\hline Sag & \multirow{5}{*}{ THD (\%) } & 9.5 & 8.95 & 8.30 \\
\hline Swell & & 8.92 & 9.20 & 8.40 \\
\hline Disturbance & & 9.50 & 10.21 & 8.56 \\
\hline Fluctuation & & 8.66 & 8.74 & 7.72 \\
\hline Interruption & & 14.31 & 14.86 & 12.02 \\
\hline
\end{tabular}

Fig. 5 illustrates the voltage sag, swell, fluctuation, distortion, and interruption and their compensation. Comparison analysis of proposed and existing techniques was carried out.Fig. 6 shows comparison analysis of DC-link voltage. Fig. 7 shows the comparison analysis of THD based on various PQ issues. Table 2 shows the comparison results of proposed and existing techniques.

\section{Conclusion}

The modeling and analysis of the PV-D-STATCOM based Power Quality control is explained in this paper. Experimental results have confirmed an improvement in the voltage for the safe operation of the DSTATCOM during the occurrence of the voltage sag, swell, fluctuation, distortion, and interruption. An effective technique with the combination of the Recurrent Neural Network (RNN) and the Tree Seed Algorithm (TSA) is utilized to analyze and control the PQ issues in grid-connected hybrid PV/WT system. The efficacy of the suggested method was compared with different conventional techniques such as CSORNN and PSO-RNN. From the analysis, it has been concluded that the suggested control technique is much effective in enhancing the PV-D-STATCOM operation of the system than other techniques. 


\section{References}

[1] Liang, "Emerging power quality challenges due to the integration of renewable energy sources", IEEE Transactions on Industry Applications, Vol.53, pp.855-866, 2016.

[2] Zhu, Yuan, and Wang, "Multi-stage active management of renewable rich power distribution network to promote the renewable energy consumption and mitigate the system uncertainty", An International Journal of Electrical Power \& Energy Systems, Vol.111, pp.436-446, 2019.

[3] Sridhar V. and S. Umashankar, "A comprehensive review on CHB MLI based PV inverter and feasibility study of CHB MLI based PV-STATCOM", An International Journal of Renewable and Sustainable Energy Reviews, Vol.78, pp.138-156, 2017

[4] Liu, Huakun, XiaorongXie, XiaodanGao, Hui Liu and Yunhong Li, "Stability Analysis of SSR in Multiple Wind Ranchs Connected to Series-Compensated Systems Using Impedance Network Model", IEEE Transactions on Power Systems, Vol.33, No.3, pp.3118-3128, 2018

[5] Panda, S., A. K. Baliarsingh, S. Mahapatraand S. C. Swain, "Supplementary damping controller design for SSSC to mitigate sub-synchronous resonance", An International Journal of Mechanical Systems and Signal Processing, Vol.68, pp.523-535, 2016

[6] Trindade, Fernanda, Thiago Ferreira, Mariana Lopes and WalmirFreitas, "Mitigation of fast voltage variations during cloud transients in distribution systems with PV solar ranchs", IEEE Transactions on Power Delivery, Vol.32, No.2, pp.921-932, 2017

[7] Varma and Siavashi, "PV-STATCOM: A new smart inverter for voltage control in distribution systems", IEEE Transactions on Sustainable Energy, Vol.21, pp.1681-91, 2018.

[8] Varma, Rajiv K., SoubhikAuddy and YsniSemsedini, "Mitigation of subsynchronous resonance in a series-compensated wind ranch using FACTS controllers", IEEE Transactions on Power Delivery, Vol.23, No.3, pp.1645-1654, 2008

[9] Mohammadpour, Hossein Ali, Amin Ghaderi, Hassan Mohammadpour and Enrico Santi, "SSR damping in wind ranchs using observed-state feedback control of DFIG converters", An International Journal of Electric Power Systems Research, Vol.123, pp.57-66, 2015

[10] Lin, Lu and Yang, "Recurrent fuzzy cerebellar model articulation neural network based power control of a single-stage three-phase grid-connected photovoltaic system during grid faults", IEEE Transactions on Industrial Electronics, Vol. 64, pp.1258-1268, 2016. 